\title{
Investigation of the Chemical Composition and Antioxidant and Antimicrobial Activities of Lobularia maritima: Potent Therapeutic Applications
}

\author{
Soumaya Kouidhi $\left(\mathbb{D},{ }^{1}\right.$ Oumaima Zidi $\left(\mathbb{D},{ }^{1}\right.$ Soukaina Abdelwahed $\left(\mathbb{D},{ }^{1}\right.$ Yasmine Souissi $\left(\mathbb{D},{ }^{1,2}\right.$ \\ Najla Trabelsi $\left(\mathbb{D},{ }^{3}\right.$ Alaeddine Redissi $\left(\mathbb{D},{ }^{1}\right.$ Manel Hamdi $\left(\mathbb{D},{ }^{1}\right.$ Emna Trabelsi $\left(\mathbb{D},{ }^{1}\right.$ \\ Yosra Amara $\left(\mathbb{D},{ }^{1}\right.$ Taher Bhiri, ${ }^{1}$ Rim Khrouf $\mathbb{D}^{1},{ }^{1}$ Boulbaba Selmi $\mathbb{D}^{4},{ }^{4}$ Sami Achour $\left(\mathbb{D},{ }^{4}\right.$ \\ Ameur Cherif $\left(\mathbb{D},{ }^{1}\right.$ Wissem Mnif ${ }^{1 D},{ }^{5,6}$ and Amor Mosbah $(\mathbb{D})^{1}$ \\ ${ }^{1}$ University of Manouba, ISBST, BVBGR-LR11ES31, Biotechpole Sidi Thabet, Ariana 2020, Tunisia \\ ${ }^{2}$ Department of Engineering, German University of Technology in Oman, P.O. Box 1816, PC 130, Muscat, Oman \\ ${ }^{3}$ Laboratory of Olive Biotechnology, Center of Biotechnology of Borj-Cédria, B.P. 901, Hammam-Lif 2050, Tunisia \\ ${ }^{4}$ Laboratory of Bioresources, Integrative Biology and Valorization, Higher Institute of Biotechnology of Monastir, \\ University of Monastir, Avenue Taher Hadded BP 74, Monastir 5000, Tunisia \\ ${ }^{5}$ Department of Chemistry, Faculty of Sciences and Arts in Balgarn, University of Bisha, P.O. Box 199, Bisha 61922, Saudi Arabia \\ ${ }^{6}$ Laboratory of Biotechnology and Valorisation of Bio-GeoRessources, Higher Institute of Biotechnology of Sidi Thabet, \\ BiotechPole of Sidi Thabet, University of Manouba, Ariana 2020, Tunisia
}

Correspondence should be addressed to Amor Mosbah; amor.mosbah@isbst.uma.tn

Received 8 August 2021; Accepted 23 November 2021; Published 16 December 2021

Academic Editor: Andrea Mastinu

Copyright (c) 2021 Soumaya Kouidhi et al. This is an open access article distributed under the Creative Commons Attribution License, which permits unrestricted use, distribution, and reproduction in any medium, provided the original work is properly cited.

\begin{abstract}
Lobularia maritima, commonly known as sweet alyssum, is an annual ornamental halophyte widely spread along the Tunisian seashore. However, little is known about the phytochemical, antioxidant, and antimicrobial activities of Lobularia maritima. The present study aimed to investigate the potential biological properties of different parts (flowers, leaves, roots, and stems) of Tunisian L. maritima using diverse extraction methods. Extracts were then studied for their antioxidant properties, and the highest antioxidant activity was presented in the roots' fractions. Added to this, flower, leaf, and root fractions showed interesting antimicrobial and antifungal activities against different Gram+ and Gram- bacteria and against Aspergillus ochraceus. Finally, the most active fractions (presenting the highest biological activities) were analyzed using silica gel purification and mass spectrometry coupled to gas chromatography (GC-MS) analysis, and different compounds were identified such as camphor, amide of oleic acids, tributyl acetylcitrate, betulinaldehyde, menthol, 1' -(butyn-3-one-1-yl)-, (1S, 2S, 5R), benzyl benzoate, 7-acetyl-6-ethyl1,1,4,4-tetramethyltetralin, 2,4-heptadienal, (E,E), and nootkaton-11,12-epoxide. This work represents the first in-depth investigation of the content of bioactive compounds from Lobularia maritima. This species could potentially be a promising source of useful compounds for therapeutic applications.
\end{abstract}

\section{Introduction}

Since prehistoric times, human beings have used natural products such as plants, fungi, animals, and microorganisms to concoct medicines and treat diseases [1]. Plants typically contain a blend of diverse phytochemicals known as secondary metabolites which have been demonstrated to act even individually or in synergy to enhance health. Interestingly, these secondary metabolites own several biological activities as antioxidants, antimicrobials, and antifungals [2-4]. Tannins, flavonoids, and alkaloids, also called polyphenols, are known to be the key metabolites ensuring the 
healing potentials of plants [5]. Phenolic compounds are widely detected in the leaves, seeds, bark, and flowers of plants and are especially known for their ability to scavenge free radicals, which lead to metabolic disorders, neurodegenerative diseases, and cardiovascular disorders [5]. Furthermore, phenolic compounds are the most studied secondary metabolites not only for their physiological functions but also for their positive effects on human health because of their antioxidant and antimicrobial potentials [6-8].

The Mediterranean region is one of the areas with the greatest plant diversity all over the world. In fact, some $10 \%$ of the world's higher plants can be found in this area, which represents only $1.6 \%$ of the Earth's surface. Around 25,000 species are found in that region, which mostly are endemic [9].

Lobularia maritima, known as sweet alyssum, is a perennial plant species from the Mediterranean region and widely used in traditional medicine [10]. This plant is recognized for producing plentiful quantities of nectar and constitutes an excellent resource of various hymenopteran parasitoids [11, 12]. The Mediterranean's climate is characterized by an important seasonality, and most species have a short flowering period that lasts for 2 or 3 months maximum. In opposition to this trend, Lobularia maritima blooms for 10 months from September to June and reaches its flowering peak in autumn [13]. Lobularia maritima is usually cultivated as a popular garden plant with white, lemon yellow, apricot, salmon, red, red-purple, purple-violet, and violet flowers [10]. Few works were conducted on this plant, and studies on Lobularia maritima were focused on cultivation and in vitro rapid propagation. The phytochemical composition of Lobularia maritima aerial part investigation showed the existence of some important flavonoids [14]. Moreover, the aerial parts' essential oil composition evidenced the presence of numerous oxygenated monoterpenes and monoterpene hydrocarbons and represented interesting antioxidant and anti-inflammatory activities [15, 16]. However, the roots' chemical compositions as well as the potential health benefits of this plant remain improperly investigated yet.

The study of medicinal plants' potential starts with preextraction and extraction procedures. In fact, an extraction methodology is a crucial step in the processing of the bioactive constituents from plant materials [17]. As a result, the determination of active components in medicinal plant extracts assists the comprehension of their pharmacological, pharmacokinetic, and toxicological mechanisms.

In this study, we investigated the polyphenol, flavonoid, and tannin content of Lobularia maritima's flowers, roots, stems, and leaves by three different extraction methods: cold maceration, Soxhlet, and effleurage methods. Plant extracts were tested for their antioxidant activity using DPPH scavenging assay. Antimicrobial and antifungal activities were investigated throughout $\mathrm{RD}$ assay. The extracted fraction and bioactive fractions were analyzed by GC-MS in order to identify their structures.

\section{Materials and Methods}

2.1. Plant Material. One kilogram of Lobularia maritima (L.) Desv., 1815 was collected in 2015 from the region of Mahdia (Ksour Essef, Tunisia, $35^{\circ} 26^{\prime} 22.0^{\prime \prime} \mathrm{N} 11^{\circ} 00^{\prime} 57.2^{\prime \prime} \mathrm{E}$ ) weekly, from February to March. The various parts of the plant, flowers, stems, leaves, and roots, were separated and crushed fresh for preparing extracts.

2.2. Indicator Strains. Indicator strains used in this study were selected on the basis of their wide pathological impact on public health and their significant resistance to antimicrobial agents. Six bacteria and two fungi were used. Test bacteria included two Gram-positive strains of Staphylococcus aureus (NR_075000.1) and Enterococcus faecalis (NR_113901.1) and four Gram-negative strains of Pseudomonas aeruginosa (NR_074828.1), Escherichia coli (NR_074882.1), Vibrio alginolyticus, and Salmonella spp. (NR_074899.1). Phytopathogenic tested fungi were Aspergillus ochraceus and Aspergillus carbonarius.

\subsection{Extraction Methods}

2.3.1. Cold Soaking. The extraction from $200 \mathrm{gr}$ of each part (stems, leaves, flowers, and roots) was performed by the cold soaking method [18] using two litres of ethyl acetate. The maceration mixture was filtrated using Whatman paper, and filtrates were concentrated at $40^{\circ} \mathrm{C}$ using a rotary evaporator from BUTCHI, in order to obtain a crude extract for each part. A triplicate extraction was performed.

2.3.2. Soxhlet Extraction. For the extraction of the specific flavor, $200 \mathrm{gr}$ of Lobularia maritima flowers was extracted with the Soxhlet method [19] using $300 \mathrm{~mL}$ of ethyl acetate and then subjected to concentration using a rotary evaporator. A triplicate extraction was performed.

2.3.3. Extraction by Enfleurage. Cold enfleurage processes were used for oil extraction. $200 \mathrm{gr}$ of Lobularia maritima flowers was put on the wax in each tray containing $200 \mathrm{gr}$ of saturated fat [20]. The flowers were replaced with fresh flowers every $24 \mathrm{~h}$ until saturation of the fat. The floral scents in the wax (pomade) were extracted by ethanol. A triplicate extraction was performed. The ethanol was evaporated, leaving the absolute enfleurage behind.

\subsection{Phytochemical Analysis of Extracts}

2.4.1. Total Phenolic Content. The total phenolic content of the extract was determined using the Folin-Ciocalteu method [21]. An aliquot of $1 \mathrm{~mL}$ of extracts appropriately diluted was mixed thoroughly with $0.5 \mathrm{~mL}$ of Folin-Ciocalteu reagent for $1 \mathrm{~min}$, followed by the addition of $4 \mathrm{~mL}$ of $7.5 \%(\mathrm{w} / \mathrm{v})$ sodium carbonate. The mixture was allowed to stand for a further $30 \mathrm{~min}$ in the dark at $40^{\circ} \mathrm{C}$, and the absorbance was measured at $760 \mathrm{~nm}$. Total phenolic content was expressed as milligram gallic acid equivalents 
per gram of dry weight (mg GAE g-1 DW) through the calibration curve with gallic acid. The experience was performed in triplicate.

2.4.2. Total Flavonoid Content. The total flavonoid content of crude extract was determined using the aluminum chloride colorimetric method [22]. In fact, $250 \mu \mathrm{L}$ of diluted methanolic extract was mixed with $1500 \mu \mathrm{L}$ of distilled water and $75 \mu \mathrm{L}$ of $5 \% \mathrm{NaNO}_{2}$ solution. After 5 min of incubation at room temperature, $150 \mu \mathrm{L}$ of $10 \%$ $\mathrm{AlCl}_{3}$ solution was added. Then, the mixture was allowed to stand for $6 \mathrm{~min}$. Finally, $500 \mu \mathrm{L}$ of $\mathrm{NaOH}$ solution $(1 \mathrm{~N})$ was added to stop the reaction. The mixture was stirred, and absorbance was measured at $510 \mathrm{~nm}$. The total flavonoid content was calculated using a calibration curve of $(+)$-catechin, and the result was expressed as mg $(+)$-catechin equivalent per gr dry weight. All samples were repeated in triplicates.

2.4.3. Estimation of Tannins. The amounts of tannins were estimated using the method of vanillin in an acidic medium as described by Brand-Williams et al. [23]. $1500 \mu \mathrm{L}$ of vanillin/methanol solution (4\%) was added to $50 \mu \mathrm{L}$ of crude extract and mixed using a vortex. $750 \mu \mathrm{L}$ of concentrated $\mathrm{HCl}$ was added, and the mixture was allowed to stand at room temperature for $20 \mathrm{~min}$. The absorbance was measured at $510 \mathrm{~nm}$. The amount of total condensed tannins is expressed as mg (+)-catechin g-1 DW. All samples were repeated in triplicates.

2.4.4. Antioxidant Properties. The antioxidant activity of the extract was determined by the 1,1-diphenyl-2-picrylhydrazyl (DPPH) assay. The DPPH assay is a simple and rapid method used to evaluate the antioxidant activity. The free-radical scavenging of all the extracts was determined as follows: $300 \mu \mathrm{L}$ of each extract was mixed with $2 \mathrm{~mL} \mathrm{DPPH}$ solution $0.01 \mathrm{mM}$ and incubated in the dark at room temperature for $1 \mathrm{~h}$. The absorbance of the mixture was then measured at $515 \mathrm{~nm}$. Methanol was used as a negative control. The ability of the sample to scavenge DPPH radicals was determined as follows:

$\%$ radical scavenging activity $=\frac{[(\text { ODcontrol }- \text { ODsample })]}{\text { ODcontrol }} * 100$.

2.4.5. EC $_{50}$ Determination and Statistical Analysis. $\mathrm{EC}_{50}$ is the concentration required to obtain a $50 \%$ antioxidant effect of a chemical extract or a drug molecule. This parameter is typically employed to express the antioxidant capacity and to compare the activity of different samples in comparison to an antioxidant standard. In this study, we calculated $\mathrm{EC}_{50}$ values of 4 plant extracts, flowers, leaves, stems, and roots, according to the method described by Benslama and Harrar [24] with modifications.
Obtained EC50 data were analyzed using one-way ANOVA to compare the antioxidant capacity of different L. maritima extracts to BHA standard. GraphPad Prism 9.2.0 software was used to perform the statistical analysis.

\subsection{Biological Study}

2.5.1. Antimicrobial Activity Tests. The antibacterial activity of organ extracts was examined by Radial Diffusion Assay (RDA). Briefly, bacteria were grown overnight as a preculture at $37^{\circ} \mathrm{C}$ in $2 \mathrm{~mL}$ trypticase soy broth (TSB). $75 \mu \mathrm{L}$ of this preculture was then inoculated into $15 \mathrm{~mL}$ of fresh TSB and incubated for an additional $2.5 \mathrm{~h}$ at $37^{\circ} \mathrm{C}$ in order to obtain midlogarithmic-phase organisms. Cultures were centrifuged at $400 \mathrm{rpm}$ for $5 \mathrm{~min}$ at $4^{\circ} \mathrm{C}$, washed once with cold $10 \mathrm{mM}$ sodium phosphate buffer, $\mathrm{pH} 7.4$ (NAPB), and suspended in $10 \mathrm{~mL}$ of the same buffer.

The optical density (OD) of an aliquot was measured at $620 \mathrm{~nm}$, based on the relationship CFU/ $\mathrm{mL}=\mathrm{OD}_{620} \times 2.5 .10^{8}$; a volume containing $4 \times 10^{6}$ bacterial CFU was added to $10 \mathrm{ml}$ of underlay gel $(10 \mathrm{mM}$ sodium phosphate buffer, $0.3 \mathrm{mg} / \mathrm{ml}$ TSB powder, and $1 \%(\mathrm{w} / \mathrm{v})$ agarose). After the deposit of $10 \mu \mathrm{L}$ of the sample in each well, the plates were incubated for $1 \mathrm{~h}$ at $37^{\circ} \mathrm{C}$ and then covered with $10 \mathrm{~mL}$ overlay gel ( $30 \mathrm{gr}$ TSB; $5 \mathrm{~g}$ agarose; qsp $500 \mathrm{~mL}$ distilled water). After incubation for $18-24 \mathrm{~h}$ at $37^{\circ} \mathrm{C}$, the diameter of the inhibition zone was measured to evaluate the antimicrobial activity.

\subsection{Chemical Characterization}

2.6.1. Chromatography on Silica Gel. L. maritime ethyl acetate extracts (leaves, flowers, and roots) were passed through silica gel columns. Extracts were fractionated according to the gradient from $100 \%$ petroleum ether $/ 0 \%$ ethyl acetate to $0 \%$ petroleum ether $/ 100 \%$ ethyl acetate with $5 \%$ increment. Fractions $(15 \mathrm{ml})$ were then collected and stored at room temperature until further use.

2.6.2. Thin-Layer Chromatography (TLC). All the fractions were checked by TLC precoated on silica gel 60 plates and developed with $\mathrm{CHCl} 3-\mathrm{MeOH}(90: 20)$. Detection was achieved with a UV lamp at 254 and $366 \mathrm{~nm}$.

2.7. Gas Chromatography Mass Analysis. The samples were analyzed using Agilent GC 7890B. An MS 240 (Agilent, CA, United States) ion trap gas chromatography (GC) system was equipped with an MS detector and HP-5MS capillary column $(30 \mathrm{~m} \times 250 \mu \mathrm{m}$, film thickness $0.25 \mu \mathrm{m})$. Injector temperature was set at $280^{\circ} \mathrm{C}$, and GC oven temperature was programmed at $40^{\circ} \mathrm{C}$ for $2 \mathrm{~min}$ and then a slope at $50^{\circ} \mathrm{C}$ up to $250^{\circ} \mathrm{C}$ maintained for $20 \mathrm{~min}$, and analysis was carried out in a full-scan mode for $60 \mathrm{~min}$. The carrier gas helium was used at a flow rate of $1 \mathrm{~mL} \mathrm{~min}^{-1} .1 \mu \mathrm{L}$ of samples was injected with the split mode and ionization range from 50 to $1000 \mathrm{mV}$. A triplicate was performed for each sample. 
2.8. Metabolites' Identification. Mass spectral data processing and metabolite identification were performed using the Automated Mass Spectral Deconvolution and Identification System (AMDIS) (AMDIS-version 2.71, 2012) and the National Institute of Standards and Technology (NIST) (version 2.0, 2011) database. The detected metabolite peaks were identified using three components within NIST; these were a match of $>800$, a $90 \%$ probability of a match to NIST library standards, and a head-to-tail comparison of the fragments [25]. A compound was considered to be present when it satisfied these 3 criteria.

\section{Results}

3.1. Yields of Different Types of Extraction. The extraction yield varied according to the studied organ, nature of the solvent, and technique of extraction used. In fact, good extraction methods prove to be a crucial step for getting extracts with acceptable yields. Results are presented in Table 1. The extraction yield is calculated based on the weight of the fresh organ. Thus, the percentage yields varied from $0.21 \%$ to $1.53 \%$.

For the floral part, our results showed that ethyl acetate fraction, based on the Soxhlet method, has illustrated the highest amount of extraction yield with $1.53 \%$ in comparison with the hexane extraction $(0.34 \%)$ and the cold effleurage technique $(0.52 \%)$. For the leaf and root fractions, the extraction yield varied from $0.21 \%$ to $1.51 \%$, respectively.

3.2. Phytochemical Analysis. A quantitative study was carried out on Lobularia maritima different organ (flowers, stems, leaves, and roots) fractions in order to identify their content on polyphenols, flavonoids, and tannins.

3.2.1. Biophenol Content. Phenolic compounds are very important for the antioxidant potential of plants by chelating redox-active metal ions, inactivating the free-radical chain from lipids, and neutralizing the peroxide conversions into reactive radicals. The total polyphenolic contents of the extracts are expressed as gallic acid equivalents (Table 2), varied from $60.845 \pm 0.03 \mathrm{mg} \mathrm{GAE} / \mathrm{g}$ (flower ethyl acetate extract) to $368.15 \pm 0.05 \mathrm{mg}$ GAE/g (root ethyl acetate extract).

3.2.2. Total Flavonoid Content. The content of total flavonoids is measured in catechin equivalents. The results showed that the ethyl acetate fraction from the leaves contained the highest value, with an estimated value of $0.432 \mathrm{mg} \mathrm{CE} / \mathrm{g}$, followed by root and flower extracts, using the same extraction solvent (Table 2). The lowest flavonoid value in this study was recorded in the ethyl acetate fraction from the stems, with an estimated value of $0.021 \mathrm{mg}$ $\mathrm{EC} / \mathrm{g} \pm 0.002$.

3.2.3. Total Tannin Content. The results showed that the ethyl acetate fraction from the stem contained the highest amounts of tannins (Table 2). It is evaluated by
$0.310 \pm 0.009 \mathrm{mg} \mathrm{EC} / \mathrm{g}$, followed by flower, leaf, and then, root with levels $0.303 \pm 0.013,0.195 \pm 0.003$, and $0.109 \pm 0.03 \mathrm{mg} \mathrm{EC} / \mathrm{g}$, respectively.

\subsubsection{Antioxidant Activity. Lobularia maritima extracts and} BHA control were investigated for the DPPH scavenging capacity. DPPH, 2,2-diphenyl-1-picrylhydrazyl radical is a stable organic free radical with an absorption band at $517 \mathrm{~nm}$. It loses this absorption when it accepts an electron or a free-radical species, resulting in a visually noticeable discoloration from purple to yellow. It can incorporate many samples in a short time span and is vulnerable enough to distinguish active ingredients at low concentrations.

Each extract was measured for its ability to scavenge $\mathrm{DPPH}$ free radicals expressed by $\mathrm{EC}_{50}$. As mentioned in Table 3, standard antioxidant BHA showed powerful antioxidant activity with $\mathrm{EC}_{50}$ equal to $0.051 \mathrm{mg} / \mathrm{mL}$. Ethyl acetate fraction from the root of Lobularia maritima has been evaluated as the most active extract with an $\mathrm{EC}_{50}=0.08 \mathrm{mg} / \mathrm{mL}$ (this $\mathrm{EC}_{50}$ value is not significantly different compared with the $\mathrm{EC}_{50}$ value of $\mathrm{BHT}$ ), while the other extracts showed a low antiradical activity with an $\mathrm{EC}_{50}$ about $4 \pm 0.01 \mathrm{mg} / \mathrm{mL}$ for flower, $4.2 \pm 0.01$ for leaf, and $3.9 \pm 0.02$ for stem (Table 3).

The high antiradical activity of root extract is probably due to its high polyphenolic content. These compounds are endowed with their high hydrogen donating ability to scavenge free radicals such as superoxide anion $\left(\mathrm{O}_{2}^{-}\right)$, hydroxyl radicals $(\mathrm{OH})$, and hydrogen peroxide $\left(\mathrm{H}_{2} \mathrm{O}_{2}\right)$ [24].

3.2.5. $E C_{50}$ Determination and Statistical Analysis. The oneway ANOVA test (Figure 1) showed very significant differences $(p<0.0001)$ in the $\mathrm{EC}_{50}$ obtained from flower, leaf, and stem extracts in comparison to the $\mathrm{EC}_{50}$ of $\mathrm{BHA}$ as a control. In fact, these extracts present low DPPH free-radical scavenging activity and were, respectively, less active than the standard $\mathrm{BHA}$, whereas root extract shows no significant difference $(p>0.05)$ to the BHA standard antioxidant activity which proves its high antioxidant potential. These results highlight the interesting potential of Lobularia maritima roots to be used as an antioxidant extract in drug, food, or biocosmetic preparations.

\subsection{Biological Tests}

3.3.1. Chromatography on Silica Gel. The flower extract $(1.5 \mathrm{~g})$ was fractionated on a silica gel column in 30 tubes. This fractionation was carried out using the following elution systems: petroleum ether/ethyl acetate. The analysis on the CCM plate of all these fractions allowed us to collect them in 6 groups of fractions denoted as F1 to F6, as mentioned in Table 4 (Table 4). The chromatographic separation of root extract $(1.4 \mathrm{~g})$ was carried out in the same way as flower extract. 30 tubes were collected and pooled into 7 fractions after TLC analysis (Table 4). The leaf extract ( $3 \mathrm{~g})$ was collected in 42 tubes and pooled into 11 fractions after TLC analysis (Table 4). 
TABLE 1: Yield (in percentage) of the different extracts.

\begin{tabular}{lccc}
\hline Extract & Extraction technique & Solvent & Extraction yield (\%) \\
\hline Leaf & Cold soaking & Ethyl acetate & 0.21 \\
\hline Stem & Cold soaking & Ethyl acetate & 0.60 \\
\hline Root & Cold soaking & Ethyl acetate & 1.51 \\
\hline \multirow{2}{*}{ Flower } & Soxhlet & Ethyl acetate & 1.53 \\
& Soxhlet & Hexane & 0.34 \\
\hline
\end{tabular}

TABle 2: Polyphenol, flavonoid, and tannin contents of Lobularia maritima organs.

\begin{tabular}{lccc}
\hline & Polyphenols $(\mathrm{mg} \mathrm{GAE} / \mathrm{g})$ & Flavonoids $(\mathrm{mg}$ CE/g) & Tannins (mg CE/g) \\
\hline Flower & $60.845 .5 \pm 0.03$ & $0.088 \pm 0.003$ & $0.303 \pm 0.013$ \\
Leaf & $147.451 \pm 0.07$ & $0.432 \pm 0.003$ & $0.195 \pm 0.003$ \\
Stem & $307.873 \pm 0.06$ & $0.021 \pm 0.002$ & $0.310 \pm 0.009$ \\
Root & $368.150 \pm 0.05$ & $0.346 \pm 0.002$ & $0.109 \pm 003$ \\
\hline
\end{tabular}

TAble 3: Antiradical efficiency $\mathrm{EC}_{50} \mathrm{mg} / \mathrm{mL}$ of organ extracts.

\begin{tabular}{lc}
\hline Extract & $\mathrm{EC}_{50} \mathrm{mg} / \mathrm{mL}$ \\
\hline Flower & $4 \pm 0.01$ \\
Leaf & $4.2 \pm 0.01$ \\
Stem & $3.9 \pm 0.02$ \\
Root & $0.08 \pm 0.01$ \\
BHA & $0.051 \pm 0.01$ \\
\hline
\end{tabular}

\subsubsection{Antimicrobial and Antifungal Activities of Different} Fraction Extracts of Lobularia maritima. Plants are rich sources of secondary metabolites with antimicrobial effects. Essential oils and extracts of various plants have shown a wide range of biological activities, especially antimicrobial effects on different groups of pathogenic organisms [26-29]. In the present study, the antimicrobial activities of the different extracts from Lobularia maritima were evaluated against two Gram+ and four Gram- bacterial strains. The study findings are presented in Table 5.

According to the results presented in Table 5, the three extracts of ethyl acetate from flowers, leaves, and roots and their fractions showed varying degrees of inhibition.

Flower fractions F2, F3, F4, F5, and F6 showed interesting antibacterial activity against all bacteria tested with inhibition comparable to the reference antibiotic gentamicin.

For antifungal activity (Table 6), only fraction number 5 showed activity against Aspergillus ochraceus. On the other hand, the bacterial strains showed a resistance via a leaf extract, whereas the fractions F3 and F11 showed an interesting activity against the two strains of Aspergillus.

The root extract showed specific antibacterial activity against salmonella in addition to the fungicidal effects of its $\mathrm{F} 2$ and F4 fractions.

From the results obtained for the three extracts and the fractions from which they were derived, it is found that they present, in most cases, interesting antibacterial activities and antifungal activities of which we have not found any study.

3.4. GC-MS Analysis. The constituents of compositions of the active crude extract of each part of Lobularia maritima were identified with GC-MS. The phytochemical profiles showed clear differences in different crude extract compositions (Figure 2). As shown in Figure 2, we could see common peaks as well as specific peaks for each extract. The GC-MS compositions of the crude extract of each part of Lobularia maritima are presented in Figure 3.

After excluding the solvent molecules, the metabolites were identified according to the NIST library standards. In the flower extract, the most abundant compound is the 2 (5H)-thiophenone (13.9\%), a 5-methyl used as an antianxiety, hypnotic, and antiepileptic drug or nootropic. The second compound is phenylethyl alcohol $(6.88 \%)$ used as a disinfectant and classified as a chemical destroying spore as well as vegetative forms of microorganisms. In the root extract, the most abundant molecule was tributyl acetylcitrate $(5.39 \%)$ used as a flavoring agent and hexahydropyrrolizine-3-thione (4.9\%) used as an antiinflammatory drug. In the leaves, the most abundant compounds were 2-4-di-tert-butyl phenol (19.53\%), 9,12,15octadecatrienoic acid (12.14\%), gamma-sitosterol (5.80\%), and n-hexadecanoic acid (5.50\%).

Taken together, the GC-MS analysis revealed the presence of 15 different bioactive phytocompounds resumed in Table 7. No report until today has been published on Lobularia maritima bioactive compound identification.

\section{Discussion}

Lobularia maritima could constitute an excellent source of various bioactive phytocompounds that assure a wide range of biological activities such as antioxidant, antimicrobial, and antifungal activities. Most of the studies on Lobularia maritima investigated the aerial part of the plant's phytochemical composition and its essential oil activities, while the roots remain unknown for their composition and activities. The aim of our work was also to study the biological properties of Lobularia maritima flower, leaf, and root extracts and their bioactive fractions. The in vitro antioxidant potential and the antibacterial and antifungal activities were investigated. 


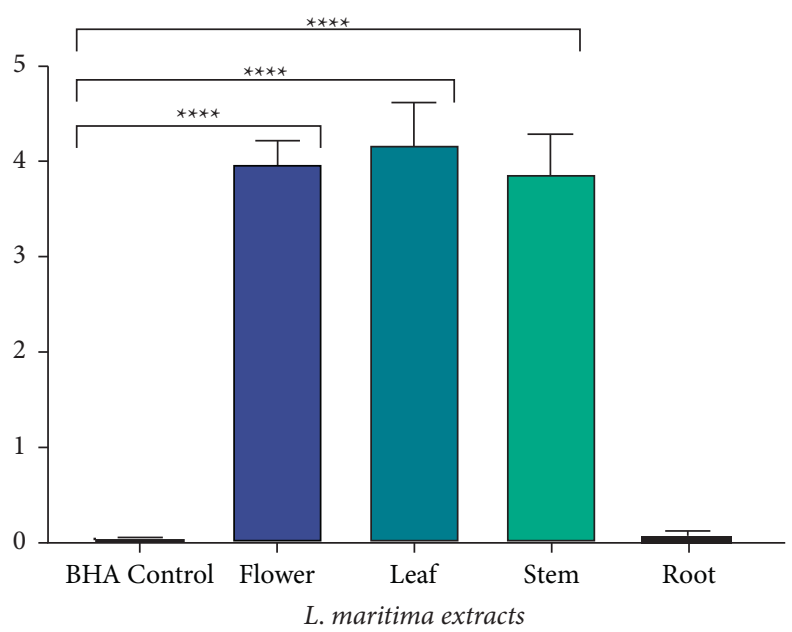

FIGURE 1: $\mathrm{EC}_{50}$ values in free radical scavenging activity of the Lobularia maritima extracts against DPPH free radical. Values were means \pm SD of triplicate (ns: $p>0.05 ;{ }^{* * * *}: p \leq 0.0001$ ).

TABLE 4: Schematic view of the fractioning result of flower, root, and leaf extracts of Lobularia maritima.

\begin{tabular}{|c|c|c|c|c|c|}
\hline \multicolumn{6}{|c|}{ Flower extract of Lobularia maritima $(1.5 \mathrm{~g})$} \\
\hline $\mathrm{F} 1(1,2,3) 80 \mathrm{mg}$ & F2 (4-10) $90 \mathrm{mg}$ & F3 (11-14) $80 \mathrm{mg}$ & F4 (15-20) $150 \mathrm{mg}$ & F5 (21-23) $110 \mathrm{mg}$ & $\begin{array}{c}\mathrm{F} 6 \\
(24-30) \\
90 \mathrm{mg}\end{array}$ \\
\hline \multicolumn{6}{|c|}{ Root extract of Lobularia maritima $(1.4 \mathrm{~g})$} \\
\hline F1 (1-2) $70 \mathrm{mg}$ & F2 (3-10) $110 \mathrm{mg}$ & F3 (11-12) $50 \mathrm{mg}$ & $\mathrm{F} 4(13-21) 130 \mathrm{mg}$ & $\begin{array}{c}\text { F6 (23-24) } \\
50 \mathrm{mg}\end{array}$ & $\begin{array}{c}\text { F7 (25-30) } \\
110 \mathrm{mg}\end{array}$ \\
\hline \multicolumn{6}{|c|}{ Leaf extract of Lobularia maritima (3 g) } \\
\hline 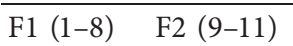 & F3 (12) & F6 (15-16) & F7 (17-20) F8 (21-22) & F9 (23-25) F10 (26-28) & F11 (29-42) \\
\hline $60 \mathrm{mg} \quad 60 \mathrm{mg}$ & $70 \mathrm{mg}$ & $110 \mathrm{mg}$ & $100 \mathrm{mg}$ & $60 \mathrm{mg} \quad 70 \mathrm{mg}$ & $80 \mathrm{mg}$ \\
\hline
\end{tabular}

Table 5: Antibacterial activity.

\begin{tabular}{|c|c|c|c|}
\hline \multirow[t]{2}{*}{ Bacterial strain } & \multicolumn{3}{|c|}{ Flower extract } \\
\hline & Active fraction & ID $(\mathrm{cm})$ & GID $(\mathrm{cm})$ \\
\hline \multirow{3}{*}{ Staphylococcus aureus } & F2 & $1.3 \pm 0.2$ & $1.2 \pm 0.1$ \\
\hline & F3 & $1 \pm 0.2$ & $1.2 \pm 0.1$ \\
\hline & $\mathrm{F} 4$ & $1.2 \pm 0.2$ & $1.2 \pm 0.1$ \\
\hline \multirow{2}{*}{ Enterococcus faecalis } & F2 & $1.4 \pm 0.2$ & $1.5 \pm 0.1$ \\
\hline & F3 & $1.2 \pm 0.2$ & $1.5 \pm 0.1$ \\
\hline \multirow{2}{*}{ Pseudomonas aeruginosa } & F3 & $1 \pm 0.2$ & $2 \pm 0.1$ \\
\hline & F6 & $2 \pm 0.3$ & $2 \pm 0.1$ \\
\hline Escherichia coli & F6 & $2 \pm 0.1$ & $2 \pm 0.1$ \\
\hline Vibrio alginolyticus & F5 & $0.5 \pm 0.1$ & nd \\
\hline Salmonella & F2 & $0.8 \pm 0.1$ & nd \\
\hline
\end{tabular}

ID: inhibition diameter of active fraction; GID: gentamicin inhibition diameter.

Based on phytochemical results, our study reported higher polyphenolic content on roots compared to the other plant organs. The total polyphenolic content of the extracts varied from $60.845 \pm 0.03 \mathrm{mg} \mathrm{GAE} / \mathrm{g}$ in flower extracts to $368.15 \pm 0.05 \mathrm{mg} \mathrm{GAE} / \mathrm{g}$ in the roots. Furthermore, we showed that Lobularia maritima was characterized by higher levels of tannins and then flavonoids with amounts from $0.109 \pm 0.03 \mathrm{mg} \mathrm{EC} / \mathrm{g}$ in roots to $0.310 \pm 0.009 \mathrm{mg} \mathrm{EC} / \mathrm{g}$ in stems. Many species belonging to Brassicaceae have been surveyed upon their flavonoid profiles from the same genus, Lobularia lybica, named "3-O- $\alpha$-L-rhamnopyranosyl $\left(1^{\prime \prime \prime} \longrightarrow 4^{\prime \prime}\right)-\beta-\mathrm{D}$-galactopyranosyl-7-O- $\alpha$-L- 
TABle 6: Antifungal activities.

\begin{tabular}{|c|c|c|c|c|c|c|c|c|c|}
\hline \multirow[t]{2}{*}{ Fungal strain } & \multicolumn{3}{|c|}{ Flower extract } & \multicolumn{3}{|c|}{ Leaf extract } & \multicolumn{3}{|c|}{ Root extract } \\
\hline & $\begin{array}{c}\text { Active } \\
\text { fraction }\end{array}$ & $\begin{array}{l}\text { ID } \\
(\mathrm{cm})\end{array}$ & GID $(\mathrm{cm})$ & $\begin{array}{l}\text { Active } \\
\text { fraction }\end{array}$ & $\begin{array}{l}\text { ID } \\
(\mathrm{cm})\end{array}$ & GID $(\mathrm{cm})$ & Active fraction & $\begin{array}{l}\text { ID } \\
(\mathrm{cm})\end{array}$ & GID $(\mathrm{cm})$ \\
\hline Aspergillus ochraceus & F5 & $1.5 \pm 0.2$ & nd & $\begin{array}{l}\text { F } 3 \\
\text { F } 11\end{array}$ & $\begin{array}{l}1 \pm 0.2 \\
1 \pm 0.2\end{array}$ & nd & $\begin{array}{l}\text { F } 2 \\
\text { F } 4\end{array}$ & $\begin{array}{l}0.9 \pm 0.2 \\
0.9 \pm 0.2\end{array}$ & nd \\
\hline Aspergillus carbonarius & nd & nd & nd & $\begin{array}{c}\text { F3 } \\
\text { F } 11\end{array}$ & $\begin{array}{c}1 \pm 0.2 \\
0.96 \pm 0.2\end{array}$ & nd & F 2 & $0.86 \pm 0.2$ & nd \\
\hline
\end{tabular}

nd: not detected; ID: inhibition diameter of active fraction; GID: gentamicin inhibition diameter.

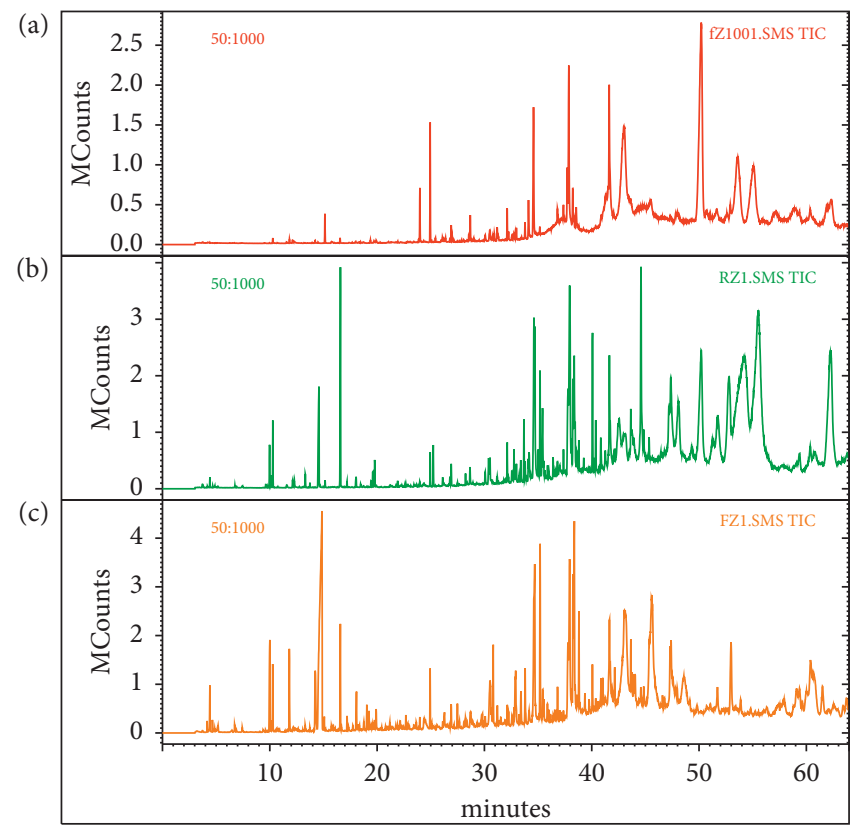

FIGURE 2: Representative GC-MS spectra of bioactive fractions from the flowers (F); the leaves (f) and the roots (R) of Lobularia maritima with retention time. (a): spectra from leaves bioactive fraction; (b): spectra from roots bioactive fraction and (c): spectra from flowers bioactive fraction.

rhamnopyranoside" [30]. Other phytochemical investigations on Lobularia maritima and other Brassicaceae species showed the presence of acylated cyanidin 3-sambubioside-5glucosides [31], glucosinolates [32], and kaempferol glycosides [14].

The radical scavenging potency was tested by means of the DPPH test. Ethyl acetate fraction from the roots of Lobularia maritima has been evaluated as the most active extract with an $\mathrm{EC}_{50}$ equal to $0.08 \mathrm{mg} / \mathrm{mL}$ which was much higher than the $\mathrm{EC}_{50}$ of flower, leaf, and stem fractions $\left(\mathrm{EC}_{50}=4 \mathrm{mg} / \mathrm{mL}\right)$. Our findings suggest that the roots have higher antioxidant potential than the aerial parts of the studied plant. Our results are much higher than those reported in a previous study that investigated the radical scavenging potency of Lobularia maritima methanol extracts from Tunisia with IC50 values equal to $253.81 \pm 1.01 \mu \mathrm{g} / \mathrm{mL}$ and $937.70 \pm 8.07 \mu \mathrm{g} / \mathrm{mL}$, for the EtOAc fraction and the raw extract, respectively [33].

Our phytochemical analysis of the different biological active compounds from crude extracts of Lobularia maritima was carried out using GC-MS. Taken together, the GC-
MS analysis revealed the presence of 15 different bioactive phytocompounds in which three are common between the different plant's parts while the others are organ-specific. The different identified compounds are terpenoids, phenols, and aldehydes.

(+)-2-Bornanone, 9-octadecenamide, (Z)-, and tributyl acetylcitrate were evidenced on the different tested active fractions. (+)-2-Bornanone, also known as camphor, is a terpenoid that is well known for its antimicrobial activity and was identified in several plants' extracts and essential oils including thyme, Cotinus coggygria, and Greek Achillea species [34-36]. 9-Octadecenamide, (Z)- is an amide of oleic acid, and its antimicrobial activity was previously reported in different studies [37-39]. Furthermore, tributyl acetyl-citrate was detected in 5 fractions of $L$. maritime flowers, roots, and leaves. This compound was described in several studies for its antifungal and antibacterial activities [37, 40].

Most of the terpenes were detected in flowers' bioactive fractions. Terpenes have been reported to have good anticancer and immunomodulatory effects [41]. In fact, betulinaldehyde, a pentacyclic triterpenoid, has been reported to 
<smiles>CC(=O)C1CCC2=CC(=O)CC(C)C2(C)C1</smiles>

Nootkaton-11,12-epoxide<smiles>O=c1c(=O)c2ccccc12</smiles>

Bicyclo[4.2.0]octa-1,3,5triene-7,8-dione

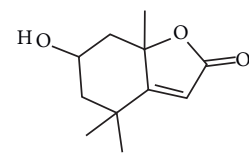

6-Hydroxy-4,4,7atrimethyl-5,6,7,7atetrahydrobenzofuran $2(4 \mathrm{H})$-one

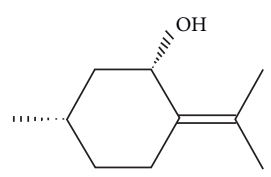

Menthol, 1'- (butyn-3-one1-yl)-, (1S,2S,5R)<smiles>C/C=C/C=O</smiles>

benzeneacetaldehyde alpha.-ethylidene-

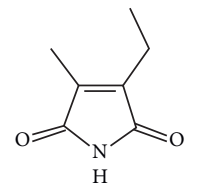

1H-Pyrrole-2,5-dione, 3-ethyl4-methyl-

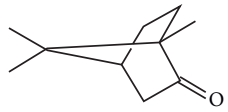

(+)-2-Bornanone<smiles>CN=CCCCCCCC[SH](C)O</smiles><smiles>CCc1cc2c(cc1C(C)=O)C(C)(C)CCC2(C)C</smiles>

Cyclohexane, isocyanato<smiles>O=C(OCc1ccccc1)c1ccccc1</smiles><smiles>CCCCCCCC/C=C\CCCCCCCC=O</smiles>

9-Octadecenamide, (Z)-

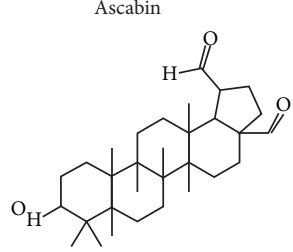

Betulinaldehyde

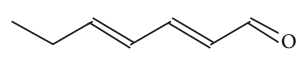

2,4-Heptadienal, (E,E)-

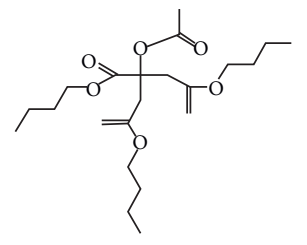

Tributylacetylcitrate

Figure 3: Compounds present in the flower, root and leave fractions of Lobularia maritima using GC-MS analysis.

TABLE 7: Summary of the detected metabolites in Lobularia maritima extracts.

\begin{tabular}{|c|c|c|c|}
\hline Chemical classes & Compounds & $\mathrm{m} / \mathrm{z}$ & $\begin{array}{l}\text { Chemical } \\
\text { structure }\end{array}$ \\
\hline Terpenoids & $(+)$-2-Bornanone & $95.999 / 81.718 / 41.513$ & $\begin{array}{c}\text { MF: } \mathrm{C}_{10} \mathrm{H}_{16} \mathrm{O} \\
\text { MW: } 152.12 \mathrm{~g} / \mathrm{mol}\end{array}$ \\
\hline Terpenoids & Betulinaldehyde & & $\begin{array}{l}\text { MF: } \mathrm{C}_{30} \mathrm{H}_{48} \mathrm{O}_{2} \\
\text { MW: } 440.7 \mathrm{~g} / \mathrm{mol}\end{array}$ \\
\hline Terpenoids & Nootkaton-11,12-epoxide & $\begin{array}{l}161.096 / 91.033 / \\
176.155\end{array}$ & $\begin{array}{c}\text { MF: } \mathrm{C}_{15} \mathrm{H}_{22} \mathrm{O}_{2} \\
\text { MW: } 234.33 \mathrm{~g} / \mathrm{mol}\end{array}$ \\
\hline Terpenoids & Menthol, 1'-(butyn-3-one-1-yl)-, (1S, 2S, 5R) & $43.72 / 41.52 / 69.162$ & $\begin{array}{c}\text { MF: } \mathrm{C}_{14} \mathrm{H}_{22} \mathrm{O}_{2} \\
\text { MW: } 222.32 \mathrm{~g} / \mathrm{mol}\end{array}$ \\
\hline Terpenoids & Neophytadiene & $68.999 / 82.793 / 59.738$ & $\begin{array}{c}\text { MF: } \mathrm{C}_{20} \mathrm{H}_{38} \\
\text { MW: } 278.5 \mathrm{~g} / \mathrm{mol}\end{array}$ \\
\hline Tetracarboxylic acids & Acetyl tributyl citrate & $\begin{array}{l}403.201 / 329.151 / \\
361.17\end{array}$ & $\begin{array}{l}\text { MF: } \mathrm{C}_{20} \mathrm{H}_{34} \mathrm{O}_{8} \\
\text { MW: } 402.5 \mathrm{~g} / \mathrm{mol}\end{array}$ \\
\hline Benzenoids & Benzyl benzoate & $105.025 / 91.054 / 77.046$ & $\begin{array}{c}\text { MF: } \mathrm{C}_{14} \mathrm{H}_{12} \mathrm{O}_{2} \\
\text { MW: } 212.24 \mathrm{~g} / \mathrm{mol}\end{array}$ \\
\hline Sulfoxides & 6-(Methylsulfinyl) hexyl isothiocyanate & $55.054 / 71.99 / 142.068$ & $\begin{array}{l}\text { MF: } \mathrm{C}_{8} \mathrm{H}_{15} \mathrm{NOS}_{2} \\
\text { MW: } 205.3 \mathrm{~g} / \mathrm{mol}\end{array}$ \\
\hline Dithiazinanes & $\begin{array}{c}\text { 6-Hydroxy-4,4,7a-trimethyl-5,6,7,7a-tetrahydrobenzofuran-2 }(4 \mathrm{H}) \text { - } \\
\text { one }\end{array}$ & $\begin{array}{l}111.999 / 43.631 / \\
178.503\end{array}$ & $\begin{array}{l}\text { MF: } \mathrm{C}_{11} \mathrm{H}_{16} \mathrm{O}_{3} \\
\text { MW: } 196.24 \mathrm{~g} / \mathrm{mol}\end{array}$ \\
\hline Aldehydes & 2,4-Heptadienal, (E,E)- & $81.999 / 110.226 / 41.191$ & $\begin{array}{c}\text { MF: } \mathrm{C}_{7} \mathrm{H}_{10} \mathrm{O} \\
\mathrm{MW}: 110.15 \mathrm{~g} / \mathrm{mol}\end{array}$ \\
\hline Phenylacetaldehydes & Benzeneacetaldehyde.alpha.-ethylidene- & $\begin{array}{c}117.069 / 131.049 / \\
78.046\end{array}$ & $\begin{array}{c}\text { MF: } \mathrm{C}_{10} \mathrm{H}_{10} \mathrm{O} \\
\text { MW: } 146.19 \mathrm{~g} / \mathrm{mol}\end{array}$ \\
\hline Fatty amides & 9-Octadecenamide, $(\mathrm{Z})$ - & $59.999 / 72.502 / 55.226$ & $\begin{array}{l}\text { MF: } \mathrm{C}_{18} \mathrm{H}_{35} \mathrm{NO} \\
\mathrm{MW}: 281.5 \mathrm{~g} / \mathrm{mol}\end{array}$ \\
\hline Triazines & Cyclohexane, isocyanato- & $67.353 / 97.713 / 82.481$ & $\begin{array}{c}\text { MF: } \mathrm{C}_{7} \mathrm{H}_{11} \mathrm{NO} \\
\text { MW: } 125.17 \mathrm{~g} / \mathrm{mol}\end{array}$ \\
\hline Others & Bicyclo [4.2.0] octa-1,3,5-triene-7,8-dione & $76.213 / 104.106 / 50.208$ & $\begin{array}{c}\text { MF: } \mathrm{C}_{8} \mathrm{H}_{4} \mathrm{O}_{2} \\
\text { MW: } 132.12 \mathrm{~g} / \mathrm{mol}\end{array}$ \\
\hline Others & 1H-pyrrole-2,5-dione, 3-ethyl-4-methyl- & $139.999 / 67.936 / 53.444$ & $\begin{array}{c}\text { MF: } \mathrm{C}_{7} \mathrm{H}_{9} \mathrm{NO}_{2} \\
\text { MW: } 139.15 \mathrm{~g} / \mathrm{mol}\end{array}$ \\
\hline
\end{tabular}


exhibit antimicrobial activities against bacteria and fungi $[41,42]$. In our study, this biomolecule was identified in active fraction 2 of the flowers and was shown to be active against $S$. aureus, Enterococcus fecalis, and Salmonella, which is in concordance with the results found in diverse studies reporting that the flower extracts exert the highest antimicrobial activity [43, 44]. According to Chung et al., betulinaldehyde was extracted from Callicarpa farinosa and was evidenced to have an effective antibacterial activity against reference and clinical methicillin-resistant (MRSA) and methicillin-sensitive S. aureus (MSSA). In their study, they described the antimicrobial effects of $\alpha$-amyrin, betuxlinic acid, and betulinaldehyde using data from the genome-wide transcriptomic analysis as multiple novel cellular targets in cell division; two-component systems, $\mathrm{ABC}$ transporters, fatty acid biosynthesis, peptidoglycan biosynthesis, aminoacyl-tRNA synthetases, ribosomes, and $\beta$-lactam resistance pathways were affected. This resulted in the destabilization of the bacterial cell membrane, inhibiting the protein synthesis and cell growth, which leads eventually to cell death [43]. Thus, betulinaldehyde could be investigated as a potential therapeutic agent for the treatment against $S$. aureus infections. Menthol, 1'-(butyn-3-one-1-yl)-, (1S, 2S, 5R) was detected in fraction 4 of flower extracts which was active against $S$. aureus. This compound was previously detected in plants known for their antibacterial and antifungal effects such as the essential oil from Aegle marmelos (L.) Corr. leaves [45] and the extracts of Cyperus rotundus rhizome [46]. Furthermore, benzyl benzoate was detected in fraction 2 of the roots. This compound was previously described in essential oil and two different extracts from Salvia urmiensis [47]. It was also demonstrated to endow with antimicrobial activity in a study conducted in the essential oil of Succisa pratensis leaves and flowers [48]. In addition, 2,4-heptadienal, (E,E)- was detected in fraction 1 of leaf extracts. It was among the identified volatile organic compounds from five Scrophularia species growing in Turkey and reported for antimicrobial and antifungal activities [49].

A study reported that 6-(methylsulfinyl)hexyl isothiocyanate (6-MSITC) is a major bioactive compound in wasabi (Wasabia japonica) [50]. Our results showed that this biomolecule was described in both flower and root fractions. In a study carried out by Beevi et al. dealing with the root, stem, and leaf of Raphanus sativus extracts for their antibacterial activities, allyl isothiocyanate (AITC) was the major ITC in the stem and leaf of $R$. sativus and showed selective antibacterial activity [51]. The bacterial growth-inhibitory ability of $R$. sativus was not dependent on the total ITC content as a low linear correlation between the total ITC content and antibacterial activity was reported [51]. Moreover, another study dealing with the antibacterial activity of Phenyl Isothiocyanate (PITC) on Escherichia coli and Staphylococcus Aureus showed that PITC has a significant antimicrobial activity on the tested bacteria [52]. PITC was proved to interact strongly with bacterial surfaces independently from the Gram type resulting in cell death [52]. When incubated with PITC, the bacterial surface became less negative and more hydrophilic. In this study, they reported that changes on surface properties may be due to the reaction of PITC with proteins at the membrane [52].
6-Hydroxy-4,4,7a-trimethyl-5,6,7,7a-tetrahydrobenzofu ran-2 $(4 \mathrm{H})$-one, also known as loliolide, was detected in fraction 1 of Lobularia maritima leaf extracts. This compound was also identified in the ethyl acetate leaf extract of Pterocarpus indicus, a common tree in the Philippines exhibiting pharmacological properties [53]. Loliolide has antimicrobial properties that were previously reported [54]. Lobularia maritima leave, root, and flower extracts seem to be rich in compounds endowed with antibacterial and antifungal activities. Several mechanisms of action were attributed to the plant's secondary metabolites. A recent review reported some of these mechanisms [55]. Among them, we can resume different effects: (a) membrane function and structure disruption (including the efflux system), (b) interruption of DNA/RNA synthesis and functions, (c) interference with intermediary metabolism, (d) induction of coagulation of cytoplasmic constituents, and (e) interruption of normal cell communication quorum sensing. Interaction with the cell membrane, diffusion through the membrane, and interaction with intracellular constituents/processes are often associated [56].

Phenols, terpenes, and aldehydes were reported as the major active essential oil components well known for their action principally performed against the cell cytoplasmic membrane [57]. Thus, the phenolic compounds were proven to contain a major antimicrobial activity in which the inactivation of the microbial enzymes is due to the presence of the hydroxyl group [57, 58]. Most probably, this group interacts with the cell membrane causing leakage of cellular components, a change in fatty acids and phospholipids distribution, and impairment of the energy metabolism and influencing genetic material synthesis $[57,59]$.

The cell membrane was also reported as the site of action of the terpenes that may permeate through it causing them to swell, thus inhibiting respiratory enzymes and causing partial dissipation of the $\mathrm{pH}$ gradient and electrical potential [60].

It was also reported that the antimicrobial mechanism of cyclic hydrocarbons is related to their lipophilic character as they increase the fluidity and permeability of the cell membrane of microorganisms. In fact, these compounds interfere with ion transport, unbalancing osmotic conditions in the membrane and making its associated proteins inefficient. These phenomena could lead to the inhibition of microbial growth and death or cell destruction [57].

\section{Conclusions}

This study showed that Lobularia maritima leave, root, and flower extracts are rich in precious phytochemical compounds endowed with biological, antibacterial, and antifungal activities. We interestingly reported that L. maritima roots exhibited high antiradical activity against DPPH free radicals in comparison to the BHA standard. In light of these findings and based on the literature, which reported promising biological activities for the majority of the identified compounds in the different Lobularia maritima extracts, we could consider that this plant could be a promising phytotherapeutic source. 
Hopefully, we are considering identifying compounds by performing further purification steps and other biological assays covering a larger scope of activities. Deep biochemical investigations should be achieved on each of these plant extracts to unravel the mechanism of action of the identified compounds. [61].

\section{Data Availability}

Data are available upon request from the last author, Dr. Amor Mosbah (amor.mosbah@isbst.uma.tn).

\section{Conflicts of Interest}

The authors declare that there are no conflicts of interest.

\section{Acknowledgments}

The authors are grateful to the ISBST, Biotechpole, Univ. Manouba, Sidi Thabet, Tunisia, for providing infrastructural facilities and assistance.

\section{References}

[1] H. Yuan, Q. Ma, L. Ye, and G. Piao, "The traditional medicine and modern medicine from natural products," Molecules, vol. 21, no. 5, p. 559, 2016.

[2] M. Orangi, A. Pasdaran, D. Shanehbandi et al., "Cytotoxic and apoptotic activities of methanolic subfractions of Scrophularia oxysepala against human breast cancer cell line," EvidenceBased Complementary and Alternative Medicine, vol. 2016, Article ID 8540640, 10 pages, 2016.

[3] E. Nikkhah, S. Asnaashari, H. Babaei, F. Heshmati Afshar, and A. Delazar, "Chemical composition and biological activities of essential oil and methanol extract of Scrophularia umbrosa," Research Journal of Pharmacognosy, vol. 4, pp. 41-50, 2017.

[4] C. Kılıç, Z. Can, A. Yılmaz, S. Yıldız, and H. Turna, "Antioxidant properties of some herbal teas (green tea, Senna, corn silk, rosemary) brewed at different temperatures," International Journal of Secondary Metabolite, vol. 4, pp. 148-154, 2017.

[5] S. K. Bhandary, N. S. K. Bhat, V. S. Bhat, P. S. K. Bhat, and M. P. Bekal, "Preliminary phytochemical screening of various extracts of punica granatum peel, whole fruit and seeds," Journal of Health and Allied Sciences NU, vol. 2, no. 4, pp. 34-38, 2012.

[6] J.-P. Rauha, S. Remes, M. Heinonen et al., "Antimicrobial effects of Finnish plant extracts containing flavonoids and other phenolic compounds," International Journal of Food Microbiology, vol. 56, no. 1, pp. 3-12, 2000.

[7] K. M. M. John, M. Ayyanar, T. Arumugam, G. Enkhtaivan, K. Jin, and D. H. Kim, "Phytochemical screening and antioxidant activity of different solvent extracts from Strychnos minor Dennst leaves," Asian Pacific Journal of Tropical Disease, vol. 5, no. 3, pp. 204-209, 2015.

[8] O. Çalişkan and A. Aytekin Polat, "Phytochemical and antioxidant properties of selected fig (Ficus carica L.) accessions from the eastern Mediterranean region of Turkey," Scientia Horticulturae, vol. 128, no. 4, pp. 473-478, 2011.

[9] M. R. González-Tejero, M. Casares-Porcel, C. P. SánchezRojas et al., "Medicinal plants in the Mediterranean area: synthesis of the results of the project Rubia," Journal of Ethnopharmacology, vol. 116, no. 2, pp. 341-357, 2008.
[10] F. Tatsuzawa, R. Usuki, K. Toki et al., “Acylated pelargonidin 3-sambubioside-5-glucosides from the red-purple flowers of lobularia maritima," Journal of the Japanese Society for Horticultural Science, vol. 79, no. 1, pp. 84-90, 2010.

[11] N. Jan, H. A. Qazi, S. Ramzan, and R. John, Biotechnologies of Crop Improvement, Springer, New York, NY, USA, pp. 1-497, 2018.

[12] J. F. Walgenbach, "Integrated pest management strategies for field-grown tomatoes," Sustainable Management of Arthropod Pests of Tomato, Elsevier, Amsterdam, Netherlands, pp. 323-339, 2018.

[13] F. X. Picó and J. Retana, "The flowering pattern of the perennial herb Lobularia maritima: an unusual case in the Mediterranean basin," Acta Oecologica, vol. 22, pp. 209-217, 2001.

[14] A. Fiorentino, A. Ricci, B. D’Abrosca et al., "Kaempferol glycosides fromLobularia maritimaand their potential role in plant interactions," Chemistry \& Biodiversity, vol. 6, no. 2, pp. 204-217, 2009.

[15] A. B. Hsouna, S. Dhibi, W. Dhifi et al., "Essential oil from halophyteLobularia maritima: protective effects against CCl4induced hepatic oxidative damage in rats and inhibition of the production of proinflammatory gene expression by lipopolysaccharide-stimulated RAW 264.7 macrophages," RSC Advances, vol. 9, no. 63, pp. 36758-36770, 2019.

[16] A. K. Gupta, S. Dhua, P. P. Sahu, G. Abate, P. Mishra, and A. Mastinu, "Variation in phytochemical, antioxidant and volatile composition of pomelo fruit (citrus grandis (L.) osbeck) during seasonal growth and development," Plants, vol. 10, no. 9, p. 1941, 2021.

[17] A. Nn, "A review on the extraction methods use in medicinal plants, principle, strength and limitation," Medicinal \& Aromatic Plants, vol. 4, no. 3, pp. 3-8, 2015.

[18] R. Davicino, A. Mattar, Y. Casali, C. Anesini, and B. Micalizzi, "Different activities of Schinus areira L.: anti-inflammatory or pro-inflammatory effect," Immunopharmacology and Immunotoxicology, vol. 32, no. 4, pp. 620-627, 2010.

[19] Q. Zhang, B. Hong, L. Zheng, X. Wang, and D. Cai, "Matrix solid-phase dispersion extraction followed by HPLC-diode array detection method for the determination of major constituents in a traditional Chinese medicine Folium isatidis (Da-qing-ye)," Journal of Separation Science, vol. 35, no. 18, pp. 2453-2459, 2012.

[20] M. Kanlayavattanakul and N. Lourith, "Volatile profile and sensory property of Gardenia jasminoides aroma extracts," Journal of Cosmetic Science, vol. 66, pp. 371-377, 2015.

[21] S. A. Baba and S. A. Malik, "Determination of total phenolic and flavonoid content, antimicrobial and antioxidant activity of a root extract of Arisaema jacquemontii Blume," Journal of Taibah University for Science, vol. 9, pp. 449-454, 2015.

[22] J. Zhishen, T. Mengcheng, and W. Jianming, "The determination of flavonoid contents in mulberry and their scavenging effects on superoxide radicals," Food Chemistry, vol. 64, no. 4, pp. 555-559, 1999.

[23] W. Brand-Williams, M. E. Cuvelier, and C. Berset, "Use of a free radical method to evaluate antioxidant activity," Lebensmittel-Wissenschaft und -Technologie- Food Science and Technology, vol. 28, no. 1, pp. 25-30, 1995.

[24] A. Benslama, A. Harrar, and A. Harrar, "Free radicals scavenging activity and reducing power of two Algerian Sahara medicinal plants extracts," International Journal of Herbal Medicine, vol. 4, no. 6c, pp. 158-161, 2016.

[25] J. M. Halket, A. Przyborowska, S. E. Stein, W. G. Mallard, S. Down, and R. A. Chalmers, "Deconvolution gas 
chromatography/mass spectrometry of urinary organic acidspotential for pattern recognition and automated identification of metabolic disorders," Rapid Communications in Mass Spectrometry, vol. 13, no. 4, pp. 279-284, 1999.

[26] M. Shams-Ghahfarokhi, M.-R. Shokoohamiri, N. Amirrajab et al., "In vitro antifungal activities of Allium cepa, Allium sativum and ketoconazole against some pathogenic yeasts and dermatophytes," Fitoterapia, vol. 77, no. 4, pp. 321-323, 2006.

[27] F. Bakkali, S. Averbeck, D. Averbeck, and M. Idaomar, "Biological effects of essential oils-a review," Food and Chemical Toxicology, vol. 46, no. 2, pp. 446-475, 2008.

[28] M. Tolouee, S. Alinezhad, R. Saberi et al., "Effect of Matricaria chamomilla L. flower essential oil on the growth and ultrastructure of Aspergillus Niger van Tieghem," International Journal of Food Microbiology, vol. 139, no. 3, pp. 127-133, 2010.

[29] S. Nabavi, A. Di Lorenzo, M. Izadi, E. Sobarzo-Sánchez, M. Daglia, and S. Nabavi, "Antibacterial effects of cinnamon: from farm to food, cosmetic and pharmaceutical industries," Nutrients, vol. 7, no. 9, pp. 7729-7748, 2015.

[30] N. Ayoub, K. A. Nematallah, A. A. Al-Gendy, and S. S. Zaghloul, "Novel quercetin glycoside with promising hepatoprotective activity isolated from Lobularia libyca (viv)," European Scientific Journal, vol. 9, pp. 177-193, 2013.

[31] F. Tatsuzawa, N. Saito, K. Shinoda, A. Shigihara, and T. Honda, "Acylated cyanidin 3-sambubioside-5-glucosides in three garden plants of the Cruciferae," Phytochemistry, vol. 67 , no. 12, pp. 1287-1295, 2006.

[32] B. Matthäus and H. Luftmann, "Glucosinolates in members of the family brassicaceae: separation and identification by LC/ ESI-MS-MS," Journal of Agricultural and Food Chemistry, vol. 48, no. 6, pp. 2234-2239, 2000.

[33] M. Marrelli, M. P. Argentieri, P. Avato, and F. Conforti, "Lobularia maritima (L.) desv. aerial parts methanolic extract: in vitro screening of biological activity," Plants, vol. 9, no. 1, pp. 89-16, 2020.

[34] K. Bayoub, T. Baibai, D. Mountassif, A. Retmane, and A. Soukri, "Antibacterial activities of the crude ethanol extracts of medicinal plants against Listeria monocytogenes and some other pathogenic strains," African Journal of Biotechnology, vol. 9, pp. 4251-4258, 2010.

[35] P. Magiatis, A.-L. Skaltsounis, I. Chinou, and S. A. Haroutounian, "Chemical composition and in-vitro antimicrobial activity of the essential oils of three Greek Achillea species," Zeitschrift für Naturforschung C, vol. 57, no. 3-4, pp. 287-290, 2002.

[36] S. Shagun, B. Sujata, and S. Manjul, "Chemical profiling, antioxidant and antibacterial properties of Cotinus coggygria essential oil from Western Himalaya," International Journal of Pharmacognosy and Phytochemical Research, vol. 8, pp. 1183-1186, 2016.

[37] H. M. Hussein, I. H. Hameed, and O. A. Ibraheem, "Antimicrobial activity and spectral chemical analysis of methanolic leaves extract of adiantum capillus-veneris using GC-MS and FT-IR spectroscopy," International Journal of Pharmacognosy and Phytochemical Research, vol. 8, pp. 369$385,2016$.

[38] I. H. Hameed, H. J. Altameme, and S. A. Idan, "Artemisia annua: biochemical products analysis of methanolic aerial parts extract and anti-microbial capacity," Research Journal of Pharmaceutical, Biological and Chemical Sciences, vol. 7, pp. 1843-1868, 2016.
[39] C. T. Seanego and R. N. Ndip, "Identification and antibacterial evaluation of bioactive compounds from Garcinia kola (heckel) seeds," Molecules, vol. 17, no. 6, pp. 6569-6584, 2012.

[40] A. H. Shobier, S. A. Abdel Ghani, and K. M. Barakat, "GC/MS spectroscopic approach and antifungal potential of bioactive extracts produced by marine macroalgae," The Egyptian Journal of Aquatic Research, vol. 42, no. 3, pp. 289-299, 2016.

[41] G. Abate, L. Zhang, M. Pucci et al., "Phytochemical analysis and anti-inflammatory activity of different ethanolic phytoextracts of artemisia annua L," Biomolecules, vol. 11, no. 7, p. 975, 2021.

[42] R. Barbieri, E. Coppo, A. Marchese et al., "Phytochemicals for human disease: an update on plant-derived compounds antibacterial activity," Microbiological Research, vol. 196, pp. 44-68, 2017.

[43] P. Y. Chung, L. Y. Chung, and P. Navaratnam, "Potential targets by pentacyclic triterpenoids from Callicarpa farinosa against methicillin-resistant and sensitive Staphylococcus aureus," Fitoterapia, vol. 94, pp. 48-54, 2014.

[44] S. Haque, D. A. Nawrot, S. Alakurtti, L. Ghemtio, J. YliKauhaluoma, and P. Tammela, "Screening and characterisation of antimicrobial properties of semisynthetic betulin derivatives," PLoS One, vol. 9, no. 7, Article ID e102696, 2014.

[45] A. K. Gupta, M. A. Rather, A. Kumar Jha et al., "Artocarpus lakoocha roxb. And artocarpus heterophyllus lam. Flowers: new sources of bioactive compounds," Plants, vol. 9, no. 10, p. $1329,2020$.

[46] M. A. H. M. Jamal, M. S. Rahman, M. B. Hossain et al., "Antibacterial properties and chemical composition of essential oil from Aegle marmelos (L.) corr. leaves growing in Bangladesh," Journal of Essential Oil Bearing Plants, vol. 20, no. 1, pp. 155-174, 2017.

[47] S. Surendran and K. Vijayalakshmi, "GC-MS analysis of phytochemicals in Cyamopsis tetragonoloba fruit and Cyperus rotundus rhizome," International Journal of Pharmacognosy and Phytochemical Research, vol. 3, pp. 102-106, 2011.

[48] M. H. Farjam, "Comparative study of the antimicrobial activity of essential oil and two different extract from Salvia urmiensis Bunge," Asian Pacific Journal of Tropical Biomedicine, vol. 2, no. 3, pp. S1680-S1682, 2012.

[49] E. Witkowska-Banaszczak and J. Długaszewska, "Essential oils and hydrophilic extracts from the leaves and flowers of Succisa pratensis Moench. and their biological activity," Journal of Pharmacy and Pharmacology, vol. 69, no. 11, pp. 1531-1539, 2017.

[50] G. Renda, Y. Kalayc1, B. Korkmaz, S. Alpay Karaoglu, and N. Yayl, "Chemical composition and antimicrobial activity of the essential oils of five Scrophularia L. species from Turkey," Records of Natural Products, vol. 11, no. 6, pp. 521-531, 2017.

[51] T. Uto, D.-X. Hou, O. Morinaga, and Y. Shoyama, "Molecular mechanisms underlying anti-inflammatory actions of 6(methylsulfinyl) hexyl isothiocyanate derived from wasabi (wasabia japonica)," Advances in Pharmacological Sciences, vol. 2012, Article ID 614046, 8 pages, 2012.

[52] S. S. Beevi, L. N. Mangamoori, V. Dhand, and D. S. Ramakrishna, "Isothiocyanate profile and selective antibacterial activity of root, stem, and leaf extracts derived from Raphanus sativus L," Foodborne Pathogens and Disease, vol. 6, no. 1, pp. 129-136, 2009.

[53] A. Abreu, A. Borges, L. Simoes, M. Saavedra, and M. Simoes, "Antibacterial activity of Phenyl isothiocyanate on Escherichia coli and Staphylococcus aureus," Medicinal Chemistry, vol. 9, no. 5, pp. 756-761, 2013. 
[54] C. Y. Ragasa, R. D. De Luna, and J. G. Hofilena, "Antimicrobial terpenoids from Pterocarpus indicus," Natural Product Research, vol. 19, no. 4, pp. 305-309, 2005.

[55] J. G. Hofileiia and C. Y. Ragasa, "A monoteroene from PttJrocarous indicus neguminosaeJ," vol. 18, pp. 5-8, 2002.

[56] N. S. Radulovic, P. D. Blagojevic, Z. Z. Stojanovic-Radic, and N. M. Stojanovic, "Antimicrobial plant metabolites: structural diversity and mechanism of action," Current Medicinal Chemistry, vol. 20, no. 7, pp. 932-952, 2013.

[57] J. Sikkema, J. A. de Bont, and B. Poolman, "Mechanisms of membrane toxicity of hydrocarbons," Microbiological Reviews, vol. 59, no. 2, pp. 201-222, 1995.

[58] R. Di Pasqua, G. Betts, N. Hoskins, M. Edwards, D. Ercolini, and G. Mauriello, "Membrane toxicity of antimicrobial compounds from essential oils," Journal of Agricultural and Food Chemistry, vol. 55, no. 12, pp. 4863-4870, 2007.

[59] S. Burt, "Essential oils: their antibacterial properties and potential applications in foods-a review," International Journal of Food Microbiology, vol. 94, no. 3, pp. 223-253, 2004.

[60] E. Ceylan and D. Y. C. Fung, "Antimicrobial activity of spices," Journal of Rapid Methods and Automation in Microbiology, vol. 12, no. 1, pp. 1-55, 2004.

[61] J. Sikkema, F. J. Weber, H. J. Heipieper, and J. A. M. D. Bont, "Cellular toxicity of lipophilic compounds: mechanisms, implications, and adaptations," Biocatalysis, vol. 10, no. 1-4, pp. 113-122, 1994. 